\title{
Study on the Impact of Large-scale Sports Events on the Soft Power of Chinese Urban Culture
}

\author{
Fan Zhang \\ Department of Police Skills and Tactics \\ Nanjing Forest Police College \\ Nanjing 210023, China
}

\begin{abstract}
By using the method of documentation, this paper makes an analysis of the impact of large-scale sports events on the promotion of urban cultural soft power. Large-scale sports events can cohesion the city centripetal force, enhance the city's attraction, expand the city's influence, and enhance the city's cultural soft power. Accordingly, the countermeasures and suggestions to enhance the soft power of urban culture by relying on large-scale sports events are put forward: integrating the events with local culture to form a distinct orientation of urban culture. Introduce high-end cultural talents to form the development pattern of urban culture in the near future. Establish the brand of urban culture and comprehensively enhance the core competitiveness of urban culture.
\end{abstract}

Keywords-Sports Management; Sports Culture; Urban Culture; Large-scale Sports Events; Urban Soft Power

\section{INTRODUCTION}

Tracing back to the origin of the soft power of urban culture, Professor Joseph first put forward the concept of "soft power" in 1990, which became the beginning of the world's research and application of "soft power" [1]. Zhang Weihai [2] a Chinese scholar, believes that the soft power of urban culture is the cultural characteristics, spiritual temperament and cultural values shared by citizens gradually formed in the process of urban development. Zhang $\mathrm{Na}$ [3] interprets this from the perspective of the combination of cultural spiritual value, cultural spiritual form and material manifestation.

Although the concept of soft power of urban culture has not yet formed a unified definition, it derives from the concept of soft power at the national level in the field of international politics. The so-called soft power of urban culture refers to the strong cultural and ideological attraction of the city in the way of material culture and spiritual culture, as well as the comprehensive strength embodied in this attraction. The core function of the soft power of urban culture is to play a role in promoting urban economic development, developing foreign economic and trade exchanges, and expanding cultural exchanges with the help of its diverse cohesion, centripetal force and influence.

Since the successful hosting of the Beijing Asian Games in 1990, China has successively hosted the Beijing Olympic Games, the Guangzhou Asian Games, the Nanjing Youth Olympic Games and other large-scale sports events. In 2022, Hangzhou won the right to host the 19th Asian Games [4]. Hangzhou became the third Chinese city to host the Asian
Games after Beijing and Guangzhou. The hosting of the Asian Games is bound to bring unprecedented speed-up and efficiency to Hangzhou's urban construction. Industry analysts estimate that the Guangzhou Asian Games will speed up urban construction by at least 5 to 10 years [5]. Thus, in the process of bidding, organizing and holding large-scale sports events, it brings not only the huge growth of the economic strength of the host city, the improvement of the software and hardware level of urban infrastructure, the improvement of the image of the city and the spiritual outlook of the citizens. More importantly, the city's cultural soft power can be significantly enhanced by holding large-scale sports events.

\section{COMPONENT ElEMENTS OF URBAN CUltural SOFT POWER}

Experts and scholars in the industry have many different views on the elements of urban cultural soft power, which can be said that different people have different opinions and wise people have different opinions. Yu Xiaoman [6] believes that the soft power of urban culture is reflected more externally in the status and level of its cultural industry development. The author believes that from the surface level, the soft power of urban culture mainly includes three basic elements: centripetal force, attraction and radiation force of urban culture.

\section{A. Urban spirit condenses the centripetal force of citizens}

The humanistic spirit of a city is a centralized integration of its cultural characteristics, humanistic temperament and personality characteristics. It is formed in a long historical and cultural accumulation, including the city's history, humanities, customs and so on. It condenses the soul of the city, represents the image of the city, and embodies the spirit of the city. It is the concrete embodiment of national spirit, the spiritual pillar of Urban Entrepreneurship development, the civilized accomplishment of citizens and the centralized feedback of moral ideals. This spiritual accumulation is formed in the long process of urban construction, and the immersion of its regional culture paves the spiritual foundation of the city. From the government to the people's cultural identity, the city spirit has the function of cultural bonding and cohesion of the people's hearts, so that the citizens can actively adjust and establish positive value pursuit, and consciously establish the happiness of individuals, families and units under the common vision of urban development. This spiritual power comes from the edification of urban culture, which in turn turns into the group consciousness and common recognition of the citizens. 
It breeds vitality for internal cohesion and shapes and wraps the image of the city outside.

\section{B. Cultural Innovation Enhances Urban Attraction}

Cultural innovation is the intrinsic motive force for cities to enter the process of modernization, the core element for leading the cultural trend of the market and participating in the cultural internationalization competition, as well as the key to focusing on the world's vision [7]. The soft power of urban culture depends not only on the accumulation, excavation and integration of traditional culture, but also on the innovation of cultural products with originality as the core. Innovation is the essential feature of culture and the unique symbol of the soft power of urban culture at a certain stage. It can inject inexhaustible impetus into the prosperity of the city. It is not only the carrier of urban cultural influence, but also includes the economic and spiritual values of culture. It has a distinct cultural orientation and determines the popularity, competitiveness and attractiveness of the city. Only on the basis of all-round development of cultural innovation can a city significantly improve its ability of cultural production and ultimately rise to the city's cultural soft power.

\section{Cultural Communication Converges into Radiation Force}

While inheriting traditional culture, according to the development needs of modern civilization and fashion culture, urban culture develops many cultural industries with multiethnic characteristics, which is the productivity of the soft power of urban culture. Because of its cultural characteristics, cultural products contain the producers' ideas, cultural concepts, aesthetic tastes and value orientations, which form a strong radiation effect through international circulation across regions and borders. With the rapid development of new media such as media digitalization and Internet, the soft power of urban culture can integrate regional culture with foreign culture through the communication, collision and integration between cities. It can derive spiritual appeal, accumulate strong radiation from the outside world, become the landmark of the construction of urban cultural soft power, and attract a large number of excellent literary and creative talents at home and abroad to the production of urban cultural innovation. Under the guidance of common cultural concepts and values, the creation of literary and artistic, music, animation and other creative products has changed consumers' thoughts and feelings imperceptibly. The broader the product dissemination area, the greater the cultural radiation, the higher the cultural taste, the stronger the attraction of the city.

\section{THE IMPACT OF LARGE-SCALE SPORTS EVENTS ON THE SOFT POWER OF URBAN CULTURE}

Sports events have the function of integrating culture. They can integrate the city's historical culture, regional culture and advanced foreign culture, enrich and expand the rich connotation of sports events with culture, and form the unique cultural core competitiveness of the city.

\section{A. Cohesion of the Centrality of Urban Culture}

The process of bidding, organizing and holding large-scale sports events is also the process of centripetal cohesion of urban cultural development. Whether the host city can achieve the desired results and whether the overall image of the city can be greatly improved depends on the cohesion of the centripetal force of urban culture. Externally, cultural communication can unite the centripetal force at home and abroad. Cultural centripetal force is the power of integration of many factors, including physical transportation, communication, venues and other hardware construction, but also intangible historical and cultural heritage, human resources and so on. In today's pluralistic world cultural development pattern, the world cultural trend of thought is increasingly fierce collision, cultural exchange and integration is more active, urban culture through the dissemination of the formation of cultural centripetal force. In order to improve the soft power of culture and enhance the international competitiveness, the host city should take the first step to strengthen the construction of cultural dissemination capacity with its own characteristics. With the opportunity of hosting propaganda for the Asian Games and relying on new media and internet, Guangzhou has strengthened the popularization of urban intangible cultural heritage. The charm of ancient humanities capital has formed a strong centripetal force at home and abroad. Its harvest is not only the improvement of popularity, but also the radiation effect of urban cultural transmission. Internally, cultural dissemination can cohere the centripetal force of the city's citizens. Successful bidding for large-scale sports events can greatly enhance the centripetal force of the general public, whose sense of honor and pride can easily stimulate the positive spirit of the citizens and strong patriotic feelings [8].

The government guides the attraction of sports events to the citizens and the centripetal force stimulated by the attraction into the main theme of sports events, integrates various social resources, and gathers all the people to run sports events well. Naturally, we can achieve the multiple effects of carrying forward the Olympic spirit, improving the ideological and moral quality of citizens, fostering social civilization, and mobilizing the whole society to participate in the construction of urban cultural soft power. With the purpose of strengthening the cohesion and centripetal force of urban culture, Nanjing successfully hosted the Youth Olympic Games. Through excavating Nanjing's cultural resources, cultivating the spirit of new citizens, carrying out moral practice activities, deepening the construction of urban civilization and other measures, it effectively improved the quality of citizens, thus forming the centripetal force centered on the spirit of the city.

\section{B. Enhancing the Attraction of Urban Culture}

The three elements of urban comprehensive strength are culture, politics and economy. Because the object of action is human, urban culture, regardless of its content and form of expression, its basic expression is attractive. The process of urban development is essentially the process of enhancing the attractiveness of urban culture, which is mainly embodied in three aspects. 
1) Gathering the heart of people and forging the spirit of the city: A city is spiritual, which is embodied in its longstanding historical context and regional cultural heritage. It embodies the history, culture and folk customs of the city, and reflects the common value orientation, cultural heritage, codes of conduct and group consciousness of the city. It has the magic charm of changing public psychology, can greatly enhance the sense of pride, honor and patriotism enthusiasm of citizens, and form a strong atmosphere of positive health, unity and upward, civilization and harmony from top to bottom. Through collecting emblems, songs, mascots, issuing commemorative stamps, torch relay and other activities, the broad masses of citizens will be gathered in a series of colorful activities to organize the event, change the values and spiritual outlook of the broad masses of citizens, and inject the Era Connotation of progress, pursuit of ideals and co-construction of civilization into the spirit of the city. In addition, it also provides tremendous spiritual impetus for the economic and social development of the city.

2) Expanding influence and attracting attention from all sides: Holding large-scale sports events can stimulate urban economic development and promote the development of cultural soft power [9]. Sports events will bring a golden opportunity for the development of the cultural soft power of the host city. It will build an interactive platform for cultural exchanges between the host city and domestic and foreign cities, open a window to show the image of the city to the world, and attract the attention of all parties at home and abroad. At the same time, large-scale sports events have the power to attract the global media, making them the focus of world public opinion, giving the world an opportunity to recognize, feel, communicate and develop. Let the outside world feel the history and culture of the host city, the city style, local customs, cultural concepts, etc., expand the visibility and international influence of the host city, and bring great potential opportunities for the development of the soft power of urban culture. For example, the Seoul Olympics quickly made South Korea one of the "four little dragons" in Asia, and the Barcelona Olympics made Barcelona the seventh most famous city in Europe [10].

3) Accelerating Innovation and Forming Cultural Highlights: Innovation is an inexhaustible motive force for cities to flourish, and the fundamental value of culture lies in innovation. Bidding and hosting large-scale sports events bring a series of opportunities for the host city to catalyze cultural innovation. From the collection of emblems, songs and mascots, the issuance of commemorative stamps, the relay of torches to the layout of opening and closing ceremonies, from the construction of sports venues, urban transportation, communications and other supporting facilities, to the construction of civic spiritual civilization and the construction of the natural and human environment matching the events. The highlights of the host city's economic, cultural, transportation, communications and other hardware and software construction will be formed in turn. These highlights will play a positive role in promoting the development of the construction industry, tourism, service industry and other tertiary industries in the host city. The holding of sports events will also promote the innovation and development of the cultural industry of radio, film and television network media, promote the upgrading of a number of original well-known cultural brands, and promote the formation of the cultural industry chain of the host city. By hosting the 2008 Olympic Sailing Race and Paralympic Sailing Race, Qingdao has injected new vitality into the cultural industry with the help of the Olympic Sailing Race, thus forming a core cultural industry group represented by sports, news publishing, culture, art, radio and film. "Sailing Capital", "Music Island", "City of Film and Television" and Qingdao International Beer Festival, China International Violin Competition and other urban cultural brands, these industries and brands have attracted the attention of hundreds of millions of audiences at home and abroad.

\section{Expanding the Radiation of Urban Culture}

1) Media Communication Accelerates Cultural Radiation: The strategic opportunity for large-scale sports events to enhance cultural soft power will undoubtedly set up an interactive platform for cultural exchanges between host cities and domestic and international cities by hosting major intercontinental sports events. Sports events strengthen the attractiveness and influence of the city through the dissemination, radiation and rendering of various media [11]. In 1998, Bangkok, Thailand hosted the 13th Asian Games for the fourth time. Through media communication and exchanges, Thailand took the initiative to "go out" to brand tourism culture, actively integrate into the world's advanced cultural trends, and at the same time "invite in" excellent cultures at home and abroad. The host city shows the Olympic spirit of "faster, higher and stronger" of sports athletes, the sports miracle inspired by this spirit, and the regional culture with the characteristics and charm of the host city. Through the dissemination of foreign culture, the culture of the host city will have great radiation and influence, stimulating great economic and social benefits, and ultimately forming the core competitiveness of urban culture and its own international influence.

2) Brand Innovation After-burning Cultural Radiation: A city is spiritual, which is embodied in its long-standing historical context and regional cultural heritage. It embodies the history, culture and folk customs of the city, and reflects the common value orientation, cultural heritage, codes of conduct and group consciousness of the city. It has the magic charm of changing public psychology, can greatly enhance the sense of pride, honor and patriotism enthusiasm of citizens, and form a strong atmosphere of positive health, unity and upward, civilization and harmony from top to bottom. Through collecting emblems, songs, mascots, issuing commemorative stamps, torch relay and other activities, the broad masses of citizens will be gathered in a series of colorful activities to organize the event, change the values and spiritual outlook of the broad masses of citizens, and inject the Era Connotation of progress, pursuit of ideals and co-construction of civilization into the spirit of the city. In addition, it also provides tremendous spiritual impetus for the economic and social development of the city. 
3) Economic Rise Boosts Cultural Radiation: Large-scale sports events are the most influential and widely participated sports events in the world. Apart from the direct income from holding sports events, after the event, the import and export trade of host cities or host countries expanded, and the cultural, economic and technological exchanges increased. On the one hand, the radiation dissemination of urban culture will attract a large number of foreign investment in finance, literary creation, tourism, real estate and other industries, and become the driving force of the host city's economic take-off. On the other hand, economic development has become a strong backing to promote cultural radiation. The Asian Games is the booster of the national economy. Tourism has become the economic pillar of Thailand, which can not be separated from the boost of the four Asian Games in Bangkok. "The Asian Games are of great significance in promoting Thailand and promoting the long-term development of tourism industry in Thailand," said Bidda, Minister of the Prime Minister's Office and Chairman of Tourism Institutions of Thailand. At present, the world economy has entered the era of "culture + tourism", "culture + finance", "culture + internet" and other industries are developing rapidly, which promotes the all-round development of urban culture and promotes the rise of urban GDP through the development of cultural industry.

\section{BASIC PATH TO PROMOTE THE SOFT POWER OF URban CULTURE IN LARGE-SCALE SPORTS EVENTS}

\section{A. Integrating Games with Local Culture to Form a Distinct Orientation of Urban Culture}

The Guangzhou Asian Games has not only become the focus of attention of the media and the public all over the world, but also showed the profound and multi-cultural background of Lingnan culture of Guangzhou to the world. The key to its success lies in the organic combination of Asian Games culture and local culture, and the development of sports events culture with profound connotations. First of all, the host city should do a good job in the deep integration of sports events and local culture. By reviewing the culture of international large-scale sports events, we can find that only by doing a good job in the connection, integration and operation of sports events and local culture, can we develop a sports event culture with distinctive features and profound implications, and ultimately form the core competitiveness of the soft power of urban culture. Hangzhou has successively held a series of large-scale sports events. Its urban cultural menu has a strong temptation. Many distinctive cultural symbols, such as Longjing tea charm, silk fashion, seal carving culture, have condensed into a label-like Hangzhou flavor. In the preparation of large-scale sports events, the host city should first take sports culture as the carrier to realize the organic combination of the Chinese civilization bred for thousands of years and the modern culture with strong color of the times. Secondly, the host city should define a distinct cultural orientation of the city, from a forward-looking cultural perspective, allocate various resources of the city, and make culture the engine and power of development and innovation. Thirdly, the host city should improve and perfect the public policies conducive to promoting the development of urban culture, formulate operational measures for the development of sports undertakings, and build a platform for mutual synergy and mutual development between cultural resources and public policies.

\section{B. Introducing high-end cultural talents to form a unique pattern of urban cultural development}

Looking back at the cities hosting large-scale sports events, the stadiums and municipal facilities left behind after the event are all places where influential international financial institutions and consortia settle down. Successive Olympic Games, Asian Games and other large-scale sports events host cities, all regard the absorption of high-end talent as one of the purposes of hosting events. The promotion of urban cultural soft power can not be separated from high-end talents. The host city should focus on stimulating cultural vitality and creativity, and allocate think tank resources for the promotion of urban cultural soft power. Establishing a green channel for high-level cultural talents in short supply, establishing a mechanism for training and using cultural talents, focusing on introducing high-level talents such as cultural entrepreneurs, original cultural products and cultural planners at home and abroad, and forming a group of top-level theoretical, academic and cultural talents. At the same time, we should formulate preferential conditions such as system, policy and treatment, introduce influential cultural celebrities and masters from home and abroad to the host city to set up studios, attract experts, scholars and elites of literary creation from home and abroad, and make the host city form a pattern of urban cultural development far and near

\section{Establishing the Brand of Urban Culture and Promoting the Core Competence of Urban Culture in an All-round Way}

Creating a city's unique cultural brand is the key to comprehensively enhance the core competitiveness of city culture. Qingdao Olympic Sailing Competition not only promotes the city's cultural strength rapidly, but also creates a large number of strategic and cultural brands that are well known overseas by virtue of the advantages of the geographical context and network formed by the Olympic culture, so that the city's cultural soft power can be enhanced through efficient brand marketing. The main ways to realize the core competition of urban culture are as follows. One is to implement the project-driven strategy of cultural industry. We should focus on building cultural industry bases and regional characteristic cultural industry clusters, scientifically plan a number of cultural industry bases with scientific spatial layout, close industrial chain links and strong radiation influence, and create characteristic cultural brands and cultural products with core competitiveness and regional identity. Second, we should do a good job in upgrading the brand of cultural industry. We will increase the strategic support of well-known brands, lead cultural innovation with high-end creativity, expand the convergence and integration of literary and creative industries with high-tech industries, and form the development and influence of original cultural brands in literary and creative industries. With the help of the market system and network system of multinational corporations, and with the help of large-scale cultural festivals, domestic and international expositions, as well as cultural exchanges between governments and non-governmental organizations, we will make every effort to develop international cultural markets 
such as tourism, entertainment and video production. Third, we should improve the policy support service system for the development of literary and creative industries. We will improve the urban public cultural service system, support and subsidize a number of key cultural industry projects and creative products with domestic and foreign market influence, form influential cultural brands and enhance the cultural core competitiveness of host cities.

\section{CONCLUSION}

To hold large-scale sports events, we must correctly handle the dialectical relationship between sports events and the development of urban cultural soft power. From the perspective of consistency between organizing sports events and the development of urban cultural soft power, we should solve the link between sports events and cultural soft power. Especially in the construction of sports facilities, the overall architectural style of stadiums and gymnasiums, the cultural characteristics of sports events and the activities related to sports events should be included in the urban construction planning, so as to make them consistent with the accumulation of urban history and culture and the urban temperament, and avoid the image project of laboring people and hurting money. At the same time, we should protect, develop and inherit the quality of sports events and cultural heritage.

\section{ACKNOWLEDGMENT}

This work was supported in part by the MOE Layout Foundation of Humanities and Social Sciences under Grant 19YJA890037.

In part by the Project of China Postdoctoral Science Foundation under Grant 2019T120441 \& 2017M611849.

In part by the Project of the Fundamental Research Funds for the Central Universities under Grant LGZD201805.

In part by the 13th Five-Year plan project of Jiangsu Education Science under Grant C-c/2018/01/11.

In part by Jiangsu Qing Lan Project under Grant 2017.

In part by Pre-research project of Nanjing Forest police College under Grant LGY201603.

In part by Nanjing Forest police College Teaching Reform Project under Grant ZD18104.

In part by Overseas Research and Study Project of Excellent Young and Middle-aged Teachers in Colleges and Universities of Jiangsu Province of 2018.

\section{REFERENCES}

[1] TONG Ping, "A Philosophical View of Enhancing the State's Cultura Soft Power," Journal of Beijing Administrative College, vol. 5, pp. 65 69, May 2010. (In Chinese)

[2] ZHANG Wei-hai, "An Interpretation of Cultural Soft Power in the Context of City Competition," Journal of Nantong Textile Vocational Technology College, vol. 13, pp. 35-38, August 2013. (In Chinese)

[3] ZHANG Na, YANG Ya-meng, "Literature on China's Cultural Soft Power," Journal of Hebei University (Philosophy and Social Science), vol. 38, pp. 156-158, July 2013. (In Chinese)

[4] LU Tianfeng, WANG Yue, "Motivation of Urban Middle Class People's Passion for Marathon Seen from Perspective of Cultural Identity and Problems," Journal of Wuhan Institute of Physical Education, vol. 52, pp. 11-16, April 2018. (In Chinese)

[5] Wang Guangan, "Analysis on Domestic Marathon Hot Based on Sociological Perspective,” Bulletin of Sport Science \& Technology, vol. 25, pp. 114-145, July 2017. (In Chinese)

[6] Yu Xiao-man, "The Connotation and Component Elements of Urban Cultural Soft Power," Contemporary Communications, vol. 22, pp. 8385, June 2011. (In Chinese)

[7] XUE Yong-min, WANG JI-chuang, "Deep Study on the Environmental Ethics--The Summary of Domestic Research on Deep Ecology in Recent Years," Journal of jinzhong university, vol. 26, pp. 43-46, September 2009. (In Chinese)

[8] Liu Li-wei, He Li-jun, "Impacts of Major Sports Events on the Construction of Urban Cultural Soft Power," China Collective Ceonomy, vol. 10, pp.138-139, June 2010. (In Chinese)

[9] You Songhui, Qin Haiquan, He Chenjue, et al., "Interactive Relationship between Sports Leisure Industry and City Development," Journal of shanghai physical education institute, vol. 35, pp. 58-62, April 2011. (In Chinese)

[10] HU Ying, LI Cui-xia, "Investigation and Analysis of Leisure Sports in a Park from Diachronic and Ecological Points of View," China Sport Science, vol. 35, pp. 16-28, August 2015. (In Chinese)

[11] JIN Yin-ri, YAO Song-ping, JIANG Zong-yue, "The Empirical Research on Structure and Formation of Urban Leisure Sports Business District," Journal of shanghai physical education institute, vol. 35, pp. 37-40, December 2012. (In Chinese) 